OCT 311995

\title{
OSTI
}

\section{Suspended Plutonium Aerosols Near a Soil Cleanup Site on Johnston Atoll in 1992}

\author{
Joseph H. Shinn \\ Cleo F. Fry \\ James Stephen Johnson
}

February 1, 1994

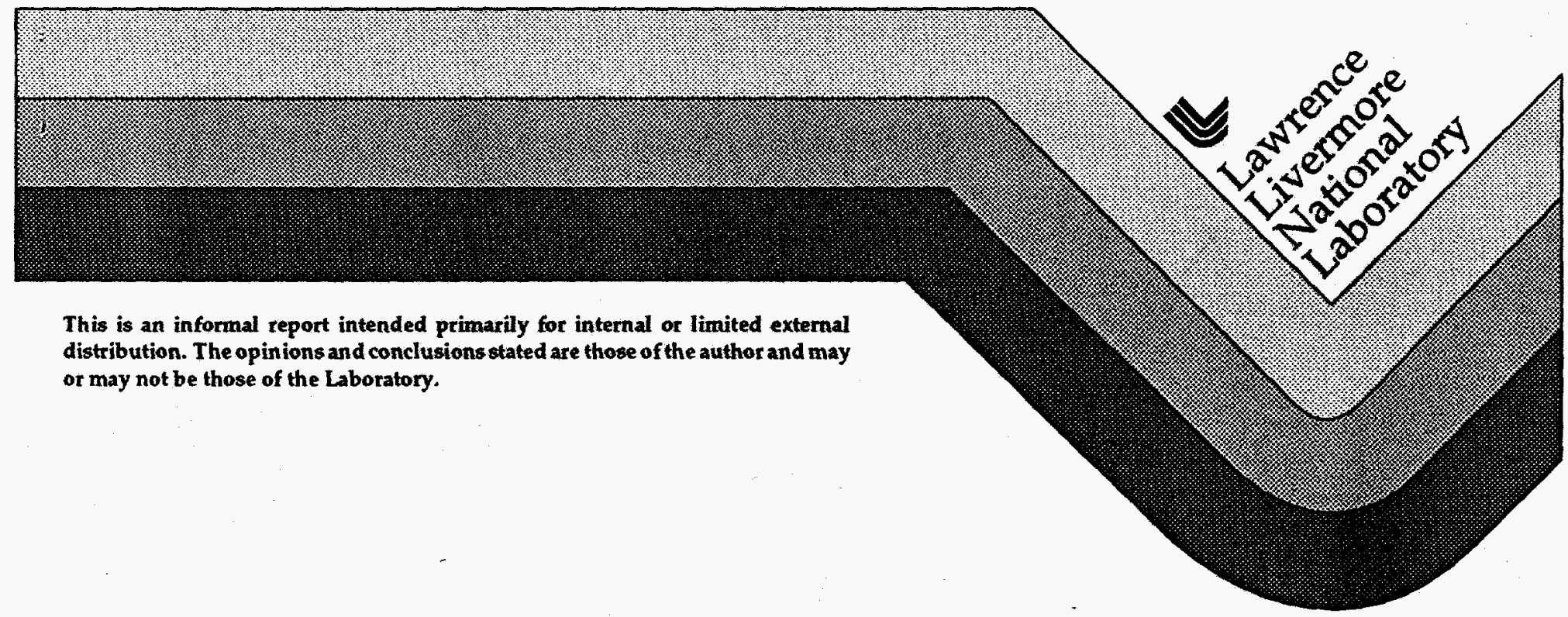




\section{DISCLAIMER}

This report was prepared as an account of work sponsored by an agency of the United States Government. Neither the United States Government nor any agency thereof, nor any of their employees, make any warranty, express or implied, or assumes any legal liability or responsibility for the accuracy, completeness, or usefulness of any information, apparatus, product, or process disclosed, or represents that its use would not infringe privately owned rights. Reference herein to any specific commercial product, process, or service by trade name, trademark, manufacturer, or otherwise does not necessarily constitute or imply its endorsement, recommendation, or favoring by the United States Government or any agency thereof. The views and opinions of authors expressed herein do not necessarily state or reflect those of the United States Government or any agency thereof. 


\section{DISCLAIMER}

Portions of this document may be illegible in electronic image products. Images are produced from the best available original document. 


\title{
SUSPENDED PLUTONIUM AEROSOLS NEAR A SOIL CLEANUP SITE ON JOHNSTON ATOLL IN 1992.
}

\author{
Joseph H. Shinn \\ Cleo O. Fry \\ James Stephen Johnson \\ Air Pathway Assessment Team \\ Environmental Characterization and Integrated Assessment Group \\ Health and Ecological Assessment Division \\ Lawrence Livermore National Laboratory
}

February 1, 1994 


\title{
SUSPENDED PLUTONIUM AEROSOLS NEAR A SOIL CLEANUP SITE ON JOHNSTON ATOLL IN 1992.
}

\begin{abstract}
Plutonium aerosol monitoring was conducted for one month near the 1992 operation of a stationary sorting system used to "mine" contaminated soil on Johnston Atoll. Pairs of high volume cascade impactors and a high volume air sampler were located at each of three locations of the process stream: the "spoils pile that was the feedstock, the "plant area" near the hot soil gate of the sorter, and the "clean pile" conveyer area where sorted clean soil was moved. These locations were monitored only during the working hours, while air monitoring was also done at an upwind, uncontaminated "background" area 24-hours per day. The three monitoring locations were extremely dusty, even though there were frequent rains during the period of operation. Total suspended particulate mass loadings were $178 \mu \mathrm{g} / \mathrm{m}^{3}$ at the spoils pile, $93 \mu \mathrm{g} / \mathrm{m}^{3}$ at the plant area, and $79 \mu \mathrm{g} / \mathrm{m}^{3}$ at the clean pile during this period, when background mass loadings were $41 \mu \mathrm{g} / \mathrm{m}^{3}$. There was no practical difference in the aerosol specific activity between the three locations, however, which had a median value of $3.64 \mathrm{pCi} / \mathrm{g}$ $(135 \mathrm{~Bq} / \mathrm{kg})$. The aerosol specific activity is enhanced by a factor of 3 over the specific activity of the processed contaminant soil. This is about the same enhancement factor as found by other studies of road traffic, bulldozing, and agricultural operations. Specific activity of processed soil was $1.35 \mathrm{pCi} / \mathrm{g}$ (50 $\mathrm{Bq} / \mathrm{kg}$ ). The median mass loading of the three downwind sites was $109 \mu \mathrm{g} / \mathrm{m}^{3}$ (uncorrected for the sea spray contribution), so that the median concentrations in air using the median aerosol specific activity was calculated to be $397 \mathrm{aCi} / \mathrm{m}^{3}(15$ $\left.\mu \mathrm{Bq} / \mathrm{m}^{3}\right)$. Measured $\mathrm{Pu}$ concentrations ranged from 280 to $1508 \mathrm{aCi} / \mathrm{m}^{3}(10$ to $\left.56 \mu \mathrm{Bq} / \mathrm{m}^{3}\right)$. During this 1992 study period the highest observed Pu-aerosol concentration value was 4000 times lower than the concentration of concern for worker exposure and 27 times lower than the Federal concentration guide to protect the general public and the environment. The aerosol aerodynamic diameters were approximately log-normally distributed with median diameters of $3.4 \mu \mathrm{m}$ (both particle mass and particle activity), but were broadly dispersed (geometric standard deviation greater than 10) over the range 0.1 to $10 \mu \mathrm{m}$.
\end{abstract}

\section{INTRODUCTION}

A system for sorting the soil contaminated by plutonium $(\mathrm{Pu})$ at Johnston Atoll, was set up to produce soil clean enough for use in landfills, while removing the high-activity, small soil volumes that are then disposed as waste (Bramlitt, 1993). We monitored the air concentrations for suspended Pu-aerosol $(239,240 \mathrm{Pu})$. and other properties that are important in assessing human exposures, during a month-long period of cleanup operation, October 14-November 14, 1992. This report provides results of measurements of total suspended particulates in massloading $\left(\mu \mathrm{g} / \mathrm{m}^{3}\right)$, specific $\mathrm{Pu}$ activity $(\mathrm{pCi} / \mathrm{g}$ or $\mathrm{Bq} / \mathrm{g}), \mathrm{Pu}$ concentration in air $\left(\mathrm{aCi} / \mathrm{m}^{3}\right.$ or $\left.\mu \mathrm{Bq} / \mathrm{m}^{3}\right)$, and median Pu-particle diameter $(\mu \mathrm{m})$. 


\section{METHODS}

Air Sampling: Two high-volume cascade impactors (CI) and one high-volume air sampler (HV) were operated as a set at each of three separate locations during the working hours near the stationary soil-sorting system. Also, two HV were operated continuously, together, at an upwind location, away from the soil contamination site. The $\mathrm{Cl}$ air samplers were the four-stage jet-plate type, Model 65-000, Anderson Air Samplers, Inc. The CI were mounted on top of a backup filter using filter holder Model FH-2100, Anderson Air Samplers, Inc. The HV were mounted on the same-type filter holder. Cellulose fiber filters, 8- X 10-inch, Whatman 41, were used in both the CI backup and the HV filter holders. This filter material is qualified by the American National Standards Institute, ANSI Standard N13.1 (reaffirmed 1993). At the face velocities in this application, for a test aerosol at $0.3 \mu \mathrm{m}$ aerodynamic diameter Whatman 41 has $70 \%$ efficiency for fragmenting aerosols and $\mathbf{9 2 - 9 4 \%}$ efficiency for solid aerosols. For larger particles, it has efficiencies greater than $98 \%$. The same filter material was also used for the perforated inter-stage impaction media for the CI. Cellulose fiber is preferred to reduce the effort required for acid dissolution after filter exposure, but to measure mass loading a special effort was required to weigh the filters (after equilibration at a reference temperature and humidity) because of the hygroscopic nature of the media. The $\mathrm{CI}$ and $\mathrm{HV}$ were powered by sealed motor-blowers (General Metal Works, Inc.) that operated without brush replacement for one month at a flow rate of $34 \mathrm{~m}^{3} / \mathrm{h}$. Flow rates and lapsed times were recorded daily, and flow rates were maintained by adjusting a variable autotransformer on each motor (VARIAC, Model 3PN116B, Superior Electric $\mathrm{Co}$.) Flow rates were monitored at a pressure tap on the motor-blower using a dial manometer (Magnhelic Model 2002C). Calibration of the flow rates was performed in the laboratory using a calibrated orifice assembly (General Metal Works, Inc., Model GMW-25), which provided a linear curve of flow rate versus the square root of pressure. Each motor was checked in the laboratory to see that it was leak-free and delivered a flow within $5 \%$ of the calibration for 34 $\mathrm{m}^{3} / \mathrm{h}$ at sea level. Flow rates on the $\mathrm{CI}$ were assured by comparing flow rate adjustments on the motor-blower with the calibration curve provided by the manufacturer and monitored at the pressure tap provided on bottom CI-plate.

The CI and HV were installed on portable tripod assemblies (General Metal Works, Inc., Model GT2200) and operated approximately $9 \mathrm{~h}$ per day during the 
working period. An operator covered the units with plastic bags for the periods when they were on standby. The operator recorded flow rates and start- and stop-times each day. The "spoils pile" set of CI and HV units was located near the feedstock where the contaminated soil was initially dumped onto a screen. The "plant area" set of $\mathrm{CI}$ and $\mathrm{HV}$ units was located at the sorter hot soil gate near where the barrels were filled with the high Pu-activity soil. The "clean pile" set of $\mathrm{CI}$ and HV units was located near the base of the conveyer unit that moved the sorted soil after it had passed successfully through the detector units. See the description of this facility for the "mining" of Pu provided by Bramlitt (1993). The "background" HV units were operated continuously, 24h per day for one month, and was located upwind where no Pu soil contamination could be found. The background HV filters were changed at the same time as other air samplers.

Soil samples: Bulk samples were collected from the surfaces of the spoils pile and the clean pile, by pooling many scoops of soil taken around and on top of the piles in a horizontally-extensive, irregular pattern, so that the pooled samples were about one $\mathrm{kg}$ in mass. These samples were intended to be representative of the soil processing operation during the period of air monitoring. The bulk samples were_forced-air dried to a low moisture content, homogenized and subdivided into $300 \mathrm{~g}$ subsamples using the same protocols as used in processing soil samples for dose assessments.

Radionuclide Analysis: Radiochemical methods were utilized to determine the $239,240 \mathrm{Pu}, 238 \mathrm{Pu}$, and $241 \mathrm{Am}$ on aerosol particles impacted on the cellulose fiber substrate. Our minimum detectability limit was $0.3 \mathrm{pCi}(0.01 \mathrm{~Bq})$ per sample for these transuranic isotopes. The isotopes were recovered by acid totaldissolution, ion-exchange separation, and electrodeposition, and measured by alpha spectrometry using internal chemical yield tracers of $242 \mathrm{Pu}$ and $243 \mathrm{Am}$. These well-documented methods were in extensive use in our studies of contamination sites around the world: Marshall Islands (Bikini, Enewetak, and Rongelap), Nevada Test Site (GMX, Little Feller, Palanquin, and Plutonium Valley), Tonopah-Nevada (Roller Coaster sites), Savannah River Lab-South Carolina (H Area), Lawrence Livermore National Lab-California (Pu-garden site), Chernobyl-Ukraine (sandy beach site, near Nuclear Power Plant Unit 4), and Palomares-Spain (site of 1966 aircraft accident). 
Quality assurance was carried out through adherence to established protocols, and by use of quality control procedures (blank filters, control filters-carried to the site and back without use, and standards). Analytical accuracy has been maintained among these methods for the analysis of $\mathrm{Pu}$ (from atmospheric fallout) in shallow or deep marine sediments or in soil and sediment samples collected from the Pacific Test Sites at Bikini and Enewetak Atolls (close-in fallout). Our method has also been used in the analysis of Pu in NIST Radioactivity Standard Reference Materials (Rocky Flats Soil and Columbia River Sediment) and in IAEA interlaboratory comparison samples. Our results have been shown to be in good agreement with those obtained using other digestion and analytical methods.

\section{RESULTS}

Specific Activity: Air samples showed that the median specific activity of $\mathrm{Pu}$ in the suspended aerosols was $3.64 \mathrm{pCi} / \mathrm{g}(135 \mathrm{~Bq} / \mathrm{Kg})$. See Table 1. The estimate of the median was obtained by calculating the mean of the natural logarithm of a list of measured specific activities and then exponentiating (ex) that value, following the method of lognormal statistics in Gilbert (1987), Chapter 13. There was no practical difference in the size distribution of specific activity between locations, when the data were closely examined. That is, there was no change in $\mathrm{Pu}$-aerosol specific activity with the size of particles collected on different CI stages. The variability between the same $\mathrm{CI}$ stages at the same location was just as great as the variability between similar stages at different locations. So the list was made by averaging data from the same two CI stages at the same location.

The list contained the Pu-activity values $(239,240 \mathrm{Pu})$ for the four stages and the backup filter of the $\mathrm{CI}$, and the HV filter as well, for the three sets of samplers in the work area $(n=18)$. The background air samplers result was excluded from this list. This estimation of the median of $3.64 \mathrm{pCi} / \mathrm{g}(135 \mathrm{~Bq} / \mathrm{Kg})$ gave a coefficient of variation (CV) of 0.54 (ratio of the standard deviation to the mean). The lognormal statistic was used because there was one high value (clean pile HV) and because it is common to find lognormal distributions among air samples. See the data summarized in Table 1. 
Table 1. Pu-Aerosol Properties on Johnston Atoll, Oct.-Nov. 1992.

\begin{tabular}{|c|c|c|c|c|c|c|}
\hline & & $\begin{array}{c}\mathrm{Pu} \\
\text { Activity } \\
\text { (pCi/g) }\end{array}$ & $\begin{array}{c}\mathrm{Pu} \\
\text { Concen. } \\
\left(\mathrm{aCi} / \mathrm{m}^{3}\right)\end{array}$ & $\begin{array}{c}\text { Mass } \\
\text { Loading } \\
\left(\mu \mathrm{g} / \mathrm{m}^{3}\right)\end{array}$ & $\underset{(\mu \mathrm{m})}{\operatorname{AMAD}}$ & $\begin{array}{c}\text { MMAD } \\
(\mu \mathrm{m})\end{array}$ \\
\hline \multirow{2}{*}{$\begin{array}{l}\text { Spoils } \\
\text { pile }\end{array}$} & $\mathrm{CI}(2)$ & 4.75 & 928 & 196 & 3.59 & 3.25 \\
\hline & HV & 3.32 & 530 & 160 & $(\mathrm{IND})^{*}$ & $(13.0)^{*}$ \\
\hline \multirow{2}{*}{$\begin{array}{l}\text { Plant } \\
\text { area }\end{array}$} & $\mathrm{CI}(2)$ & 3.20 & 310 & 96.8 & 3.64 & 3.98 \\
\hline & HV & 3.87 & 346 & 89.5 & $(9.1)^{*}$ & $(7.7)^{*}$ \\
\hline \multirow{2}{*}{$\begin{array}{l}\text { Clean } \\
\text { pile }\end{array}$} & $\mathrm{CI}(2)$ & 3.19 & 280 & 87.9 & 2.62 & 3.26 \\
\hline & HV & 21.2 & 1508 & 71.0 & $(12.5)^{*}$ & $(8.5)^{*}$ \\
\hline All Sites & $\begin{array}{l}\text { Median } \\
\mathrm{CV}^{* *}\end{array}$ & $\begin{array}{l}3.64 \\
0.54\end{array}$ & $\begin{array}{c}397 \\
0.68\end{array}$ & $\begin{array}{l}109 \\
0.41\end{array}$ & $\begin{array}{l}3.3 \\
0.58\end{array}$ & $\begin{array}{l}3.5 \\
0.42\end{array}$ \\
\hline $\begin{array}{l}\text { Back- } \\
\text { ground }\end{array}$ & $\mathrm{HV}(2)$ & 0.14 & 5.8 & 41.4 & - & - \\
\hline
\end{tabular}

*Observed geometric standard deviations; IND = indeterminate.

${ }^{* *}$ Coefficient of variation - ratio of sample standard deviation to sample mean.

The median specific activity of $3.64 \mathrm{pCi} / \mathrm{g}(135 \mathrm{~Bq} / \mathrm{kg})$ for $239,240 \mathrm{Pu}$ aerosols may be slightly enhanced over the specific activity of the soil being processed. Values of specific activity for about $15,000 \mathrm{Mg}$ of soil processed in 1992, had a median specific activity of $1.35 \mathrm{pCi} / \mathrm{g}(50 \mathrm{~Bq} / \mathrm{kg}$ ) with $\mathrm{CV}=0.47, \mathrm{n}=8$ (Bramlitt, 1993). Our soil samples collected from the spoils pile and clean pile had a median of $1.2 \mathrm{pCi} / \mathrm{g}(44 \mathrm{~Bq} / \mathrm{kg})$ with $\mathrm{CV}=0.59, \mathrm{n}=5$, essentially the same as Bramlitt's value.

Taking the ratio of specific activity in the aerosol to specific activity in the soil defines the enhancement factor, or $(3.64 / 1.35)=2.7$, to $(3.64 / 1.2)=3.0$. Shinn (1992) reported enhancement factors for 239,240 Pu aerosols during activities such as soil thawing, bulldozer blading, vacuum cleanup, wildfire, and raked-off surface, that had a range of 2.2 to 6.5. Values of enhancement factor calculated from $137 \mathrm{Cs}$ in suspended dust during agricultural tractor operations near Chernobyl gave a range of values for 2.8 to 8.4 in the observations of Loshchilov et al (1992). Hence the enhancement factor of 2.7 to 3.0 for the soil "mining" 
operation at Johnston Atoll is in the lower end of this range, and about what one would expect to observe.

Mass Loading and Pu-Aerosol Concentrations: The median mass loading for the total amount on the $\mathrm{CI}$ and on the $\mathrm{HV}$ in the work area was $109 \mu \mathrm{g} / \mathrm{m}^{3},(\mathrm{CV}=$ 0.41), but this value also contains some mass which did not come from the soil, and originated in the sea spray. For example, the two upwind background HV measured $41 \mu \mathrm{g} / \mathrm{m}^{3}$, and we did not determine the concentration of sea salt present. Nevertheless, by multiplying the median mass loading by the median specific activity, we obtain a calculated $239,240 \mathrm{Pu}$-aerosol concentration of 397 $\mathrm{aCi} / \mathrm{m}^{3}\left(15 \mu \mathrm{Bq} / \mathrm{m}^{3}\right)$ for the one-month period with $\mathrm{CV}=0.68$. Measured values of air concentration ranged from 280 to $1508 \mathrm{aCi} / \mathrm{m}^{3}\left(10\right.$ to $\left.56 \mu \mathrm{Bq} / \mathrm{m}^{3}\right)$. The upwind, background mean 239,240 Pu-aerosol concentration was $5.8 \mathrm{aCi} / \mathrm{m}^{3}$ $\left(0.21 \mu \mathrm{Bq} / \mathrm{m}^{3}\right)$. This air concentration is very close to world-wide background. For example, 1992 monitoring of 239,240Pu-aerosol concentration at the Nevada Test Site (DOE, 1993) showed that for 103 measurements in areas far from sites of soil contamination, the background level was $3.8 \mathrm{aCi} / \mathrm{m}^{3}\left(0.14 \mu \mathrm{Bq} / \mathrm{m}^{3}\right)$.

The derived concentration guide (DCG) for radiation protection of the public and the environment for $239,240 \mathrm{Pu}$ (Lung Retention Class $\mathrm{Y}$ ) is $40,000 \mathrm{aCi} / \mathrm{m}^{3}(1480$ $\left.\mu \mathrm{Bq} / \mathrm{m}^{3}\right)$. This value is used by U.S. Department of Energy, and proposed in Federal Rule 10 CFR Part 834 (Federal Register, Vol. 58, No. 56, March 25, 1993). The rule for.workers is less stringent and the permitted-exposure derived air concentration (DAC) is 150 times larger. We found that for 1992, the median value 239,240Pu-aerosol concentration of $397 \mathrm{aCi} / \mathrm{m}^{3}\left(15 \mu \mathrm{Bq} / \mathrm{m}^{3}\right)$ was 100 times lower than the DCG for the general public, and 15,000 times lower than the DAC for workers. The highest value observed, $1508 \mathrm{aCi} / \mathrm{m}^{3}\left(56 \mu \mathrm{Bq} / \mathrm{m}^{3}\right)$ was 27 times lower than the DCG for the general public, and 4000 times lower than the DAC for workers. Therefore, we do not find that the soil processing poses any significant risk to human health or to the environment.

The location-specific, mean $239,240 \mathrm{Pu}$-aerosol concentrations obtained by averaging the $\mathrm{CI}$ and $\mathrm{HV}$, were $729 \mathrm{aCi} / \mathrm{m}^{3}\left(27 \mu \mathrm{Bq} / \mathrm{m}^{3}\right)$ at the spoils pile, 328 $\mathrm{aCi} / \mathrm{m}^{3}\left(12 \mu \mathrm{Bq} / \mathrm{m}^{3}\right)$ at the plant area, and $894 \mathrm{aCi} / \mathrm{m}^{3}\left(33 \mu \mathrm{Bq} / \mathrm{m}^{3}\right)$ at the clean pile. The value at the clean pile is suspected to be non-representative, however, because the HV (Table 1) had the highest Pu specific activity of all air samples, while the $\mathrm{CI}$ showed the activity to be about the same as other air samples. It is 
thought that a "hot particle" could have caused this deviation in the sample. (Differences from the mean values, comparing the $\mathrm{CI}$ and $\mathrm{HV}$ within a set location, were $\sim 200 \mathrm{aCi} / \mathrm{m}^{3}, \sim 18 \mathrm{aCi} / \mathrm{m}^{3}$, and $\sim 614 \mathrm{aCi} / \mathrm{m}^{3}$, respectively, which is about $27 \%, 5 \%$, and $69 \%$ relative to their respective means).

Mass loading data (Table 1) showed that the amount of total suspended particulates varied between locations. This would be expected since the amount of dust generated by particular equipment in the "mining" operation would be varied, as would the arbitrary selection of location for the air samplers relative to the wind direction and distance from the local source of dust. The median value, $109 \mu \mathrm{g} / \mathrm{m}^{3}$, would be more characteristic of the potential worker exposure, but the average total suspended particulate mass loadings were $178 \mu \mathrm{g} / \mathrm{m}^{3}$ at the spoils pile, $93 \mu \mathrm{g} / \mathrm{m}^{3}$ at the plant area, and $79 \mu \mathrm{g} / \mathrm{m}^{3}$ at the clean pile during the monitoring period, when background mass loadings were $41 \mu \mathrm{g} / \mathrm{m}^{3}$. The three monitoring locations were extremely dusty, even though there were frequent rains during the period of October 14-November 14, 1992. (Differences from the mean values, comparing the $\mathrm{CI}$ and $\mathrm{HV}$ within a set location, were $\sim 18 \mu \mathrm{g} / \mathrm{m}^{3}$, $\sim 4 \mu \mathrm{g} / \mathrm{m}^{3}$, and $\sim 8 \mu \mathrm{g} / \mathrm{m}^{3}$, respectively, which is $10 \%$ or less, relative to their means).

Aerodynamic Particle Size: Particle-size distributions were calculated from the CI data, and verified graphically. We used a computational method that fits the cumulative fraction observed at each CI stage to the logarithm of the $50 \%$-cutoff aerodynamic diameter of each stage. When this cumulative fraction is converted to the integrated error-function variable and treated as a dependent variable versus the logarithm of particle diameter, a linear curve will result if the particlesize distribution is "log-normal". Our computational method will fit a straight line by least-squares analysis, determine the two parameters (median and geometric standard deviation) of the log-normal distribution, test the goodness of fit to the distribution, and provide error estimates.

The median aerodynamic diameters (MAD) for the three locations for both mass loading (MMAD) and Pu-aerosol activity (AMAD) were essentially the same, 3.4 $\mu \mathrm{m}$, with $\mathrm{CV}=0.5$; see Table 1 . The geometric standard deviations of the (approximately) log-normal distributions had a mean value of 10 , with $\mathrm{CV}=0.22$. This type of distribution can best be described as widely-dispersed, but the shape of the distribution is meaningless. The value of 10 arises because nearly all of the 
mass or the Pu-activity is found on the first $\mathrm{CI}$ stage and the backup filter, and if one truly had a log-normal distribution there would be $2 \%$ of the material below a diameter of $0.034 \mu \mathrm{m}$, and $2 \%$ greater than $340 \mu \mathrm{m}$. But these extremes are well-beyond the real range of interest. This widely-dispersed distribution is undoubtedly present because of the mechanical generation of dust from the feedstock and soil-processing. From a human health assessment viewpoint it makes almost no difference in the MAD, nor the shape of this wide distribution, because the pulmonary (deep lung) retention of the particles would remain the same for a wide range of MAD, and the tracheo-bronchial retention should be only slightly dependent on MAD.

Quality Assurance and Isotopic Ratios: Isotopic ratios were used to determine if any of the sample analysis results could be due to possible laboratory errors, such as sample cross-contamination or recording errors. Alpha spectral analysis provides $239,240 \mathrm{Pu}, 238 \mathrm{Pu}$, and $241 \mathrm{Am}$, as separate determinations on the same sample. Our results show that the median ratios were as follows:

$$
\begin{aligned}
& 239,240 \mathrm{Pu} / 241 \mathrm{Am}=4.5 \text { with } \mathrm{CV}=0.39, \mathrm{n}=32 \\
& 239,240 \mathrm{Pu} / 238 \mathrm{Pu}=30 \text { with } \mathrm{CV}=1.00, \mathrm{n}=23
\end{aligned}
$$

In the case of $238 \mathrm{Pu}, 11$ of the samples were below the detectability limit, and the mean relative standard deviation of determination was $29 \%$ with a range $9 \%$ to $63 \%$. For $241 \mathrm{Am}, 2$ of the samples were below the detectability limit, and the mean relative standard deviation of determination was $13 \%$ with a range $4 \%$ to $46 \%$. For $239,240 \mathrm{Pu}$, all 34 of the samples were detectable, and the mean relative standard deviation of determination was $7 \%$ with a range $2 \%$ to $25 \%$. The recovery of the tracer was $35 \%$ on the average with a $\mathrm{CV}=0.43$. By comparing the isotopic analyses for the same sample, it was determined that all analyses were probabalistically valid; that is, there were no sample results with statistically invalid values beyond the range of predicted values determined from the above isotopic ratios and $\mathrm{CV}$. The precision of our air samples was about $1.3 \mu \mathrm{Bq} / \mathrm{m}^{3}$, when the flow volume is taken into account.

\section{CONCLUSIONS}

The plutonium aerosol monitoring for one month in 1992, October 14-November 14, during operation of a stationary soil sorting system on Johnston Atoll showed that there should be no concern for worker exposure or for protection of the 
general public and the environment, even in the worst case observed. During this time period, the median level of Pu-aerosol concentration was 100 times lower than the Federal derived concentration guide for the public and the environment, and 15,000 times lower than the derived air concentration to protect workers. The median Pu-specific activity of suspended aerosols was 3.64 $\mathrm{pCi} / \mathrm{g}(135 \mathrm{~Bq} / \mathrm{kg})$ and the median mass loading of total suspended particulates was $109 \mu \mathrm{g} / \mathrm{m}^{3}$. The median $\mathrm{Pu}$-aerosol concentration was $397 \mathrm{aCi} / \mathrm{m}^{3}$ (15 $\left.\mu \mathrm{Bq} / \mathrm{m}^{3}\right)$. The median aerodynamic diameter of suspended mass and $\mathrm{Pu}-$ activity was $3.4 \mu \mathrm{m}$. It was found that the soil processing system caused the aerosols to be slightly enhanced in Pu-specific activity by a factor of 2.7, compared to the soil being sorted. This enhancement factor was in the range of factors reported in the literature for Pu-aerosols due to mechanical disturbance of soil.

\section{ACKNOWLEDGMENTS}

This study was supported by the Defense Nuclear Agency, Kirtland Air Force Base, Albuquerque, New Mexico (Dr. E. T. Bramlitt). We wish to thank members of the Health and Ecological Assessment Division, Lawrence Livermore National Laboratory: Dr. William Robison, Principal Investigator, Marshall Island Radioecology Program, for his technical and logistical support, and Kai M. Wong and Henry $\mathrm{E}$. Jones for their plutonium radiochemistry. 


\section{REFERENCES}

1. Bramlitt, E.T, 1993, Experience in Mining Plutonium for Soil Cleanup, p 2732, in Proceedings of the 1993 International Conference on Nuclear Waste Management and Environmental Restoration, Prague, Czech Republic, Sept. 5-11, 1992, Vol. 2, eds. P.-E. Ahlstroem, C. C. Chapman, R. Kohout, and J. Marek, American Society of Mechanical Engineers, 345 47th St., United Engineering Center, New York, N.Y., 10017.

2. Gilbert, R. O., 1987, Statistical Methods for Environmental Pollution Monitoring, Van Nostrand Reinhold Publishing, New York, 320pp.

3. Shinn, J. H., 1992, Enhancement Factors for Resuspended Aerosol Radioactivity: Effects of Topsoil Disturbance, p1183-1193, in proceedings of the Fifth International Conference on Precipitation Scavenging and AtmosphereSurface Exchange Processes, Richland, Washington, U.S.A., 15-19 July 1991, Vol. 3 , eds. S. E. Schwartz and W. G. N. Slinn, Hemisphere Publishing Corp., Washington and Philadelphia.

4. Loshchilov, N. A., Kashparov, V. A., Yudin, E. B., Protsak, V. P, and Yoshchenko, V. I., 1992, Inhalation Intake of Radionuclides during Agricultural Work in Areas Contaminated as a Result of the Chernobyl Reactor Accident, Ukrainian Institute of Agricultural Radiology, Kiev, Ukraine (in English).

5. DOE (1993), U. S. Department of Energy Nevada Operations Office, Annual Site Environmental Report - 1992, eds. S. C. Black, Alan R. Latham, and Yvonne E. Townsend, U. S. Department of Energy, Report DOE/NV/10630-66, Vol II, Appendices, September 1993. 